\title{
An Automated Tool for Inspection of Requirements Engineering Techniques
}

\author{
Mona Batra, Archana Bhatnagar
}

\begin{abstract}
From last few decades, researchers and practitioners have well recognized the significance of Requirements Engineering. Requirements Engineering stage is the foundation stone on which the entire building named software can be built. There are several Requirements Engineering (RE) techniques exists but requirements engineer choose a specific technique for a particular software project with their own preferences or organization standards. There is not only little guidance available for analyzing Requirements Engineering techniques but also all the existing researches focus on qualitative measures. There is no consideration of physical measures while analyzing and accepting a technique for a particular project. Nowadays customers satisfaction is also gaining great importance so customer perspective should also be taken into account. We have performed deep literature review and noted that analysis and selection of Requirements Engineering technique should consider all relevant attributes of each techniques and their mapping with project, people or other factors. There is a need to thoroughly comprehend and evaluate all the existing techniques with respect to analyst preferences, client experiences, project attributes, software process model characteristics. To do so, fuzzy clustering method is implemented in MATLAB. The key emphasis of this paper is to study and list all possible Requirements Engineering techniques related to Elicitation, Prioritization, Documentation, Verification and Validation, etc. The research work also analyzes attributes of each RE technique using Fuzzy $C$ mean clustering and $K$ mean clustering methods. The results of clustering provide a set of techniques, from which requirements engineer can select for specific phase of Requirements Engineering. The substantiation of the research work is done with the help of a case study that is having some known problem domain characteristics.
\end{abstract}

Keywords: Software Engineering, Requirements Engineering, Technique Selection, Clustering, Requirement Elicitation, Elicitation Techniques etc.

\section{INTRODUCTION}

The elementary purpose of Software Engineering (SE) is to strategize, implement and maintain high standardized and qualitative software products within the pre-agreed budget and in predictable time duration. Conflicting this motive of software engineering, researches illustrates that most of the software projects fail due to issues like poor requirements, missing requirements, conflicting requirements, inappropriate quality, schedule and cost [16][18]. Requirements Engineering (RE) stage is a central part in application development that produces comprehensive qualitative application software [1][2][3][20]. Complete understandable requirements eliminate misinterpretations and faults in earlier stage of development. As the system

Revised Version Manuscript Received on September 16, 2019.

Mona Batra, Research Scholar, Department of CSE, Birla Institute of Technology, Mesra, Ranchi, Jaipur Campus, Rajasthan, India

Archana Bhatnagar, Assistant Professor, Department of CSE, Birla Institute of Technology, Mesra, Ranchi, Jaipur Campus, Rajasthan, India starts to be developed, the time and the cost of fixing these errors goes farther. To perform qualitative requirements engineering, analyst or requirements engineer should have in-depth knowledge and understandability of all RE techniques and other situational characteristics that impact the software project development. Presently, there are plenty of techniques available that illustrates all different facets of the RE process and their support to implement several types of projects [7]. Though, the applicability of RE technique with respect to particular software project is not known in advance due to its intrinsically indefinite nature. This is the biggest challenge confronted by all requirements engineers' group. Therefore, up till now very inadequate literature work has been published that helps to analyze RE techniques [14][8][9][4].

However, existing researches does not deliver adequate amount of information about RE techniques analysis. Hence, a logical linking between available RE techniques and factors affecting the selection process is required. There is a need to build a framework that helps the analyst or requirements engineer to understand which techniques is better for what situation and related to project perspective, analyst preferences, client experiences, software process model characteristics. This part of our research shows how to analyze various attributes with respect to RE techniques.

The goal of this research work is to study and analyze all possible requirements engineering techniques related to Elicitation, Prioritization, Documentation, Verification and Validation, etc. All the attributes of requirement engineering techniques are analyzed and input matrix is formed comprehending weight to each attribute. We have used Fuzzy $\mathrm{C}$ mean clustering and $\mathrm{K}$ mean clustering algorithm to create clusters that suggest set of RE techniques for Elicitation, Documentation, Prioritization, Verification and Validation as per input matrix. This research work is an automated tool that perform attribute analysis of each RE techniques and create a recommendation space. A recommendation space is an assemble(group) of techniques that suggest RE techniques for a given set of problem domain variables i.e. project attributes like project complexity, size, experience, time constrain, cost, safety criteria, dynamicity, experience of project team etc. In the present automation tool, if there is a change occur in the environment variables then it will update the recommendation space with respect to changed variables.

The systematization of this paper is as follows. The methodology for analyzing RE techniques is described in section II. Section III, describes an overview of study and

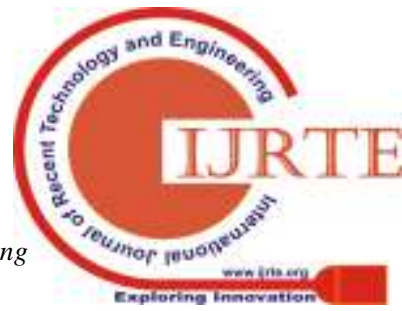


listing of all possible requirement engineering techniques. In Section IV identification and analysis of attributes of requirement engineering techniques is explained whereas Section V explains basic clustering algorithm for technique selection. Case study for evaluation of the methodology is described in Section VI. At the end, conclusion is presented in Section VII.

\section{METHODOLOGY FOR ANALYZING REQUIREMENTS ENGINEERING TECHNIQUES}

The techniques listed in Table1 are the selected demonstrative RE techniques that widely known in industry and possess well-defined scope in major phases of the RE process. This mechanism categorized and analyzed each technique. This mechanism offers a means to describe major properties, advantages and constraints of each technique, that can be depicted as attributes. Set of rules is used to assign weight for each attribute for further classification and perform clustering to get recommended space (group of RE techniques) for software under construction. Analysis of requirements engineering techniques comprises of below three steps:

I. Study and listing of all possible requirements engineering techniques.

II. Identification and Analysis of attributes of requirement engineering techniques and formation of input matrix.

III. Detailed analysis of each technique using fuzzy clustering method.

Subsequent sections explain in details about the whole technique analysis process.

\section{STUDY AND LISTING OF ALL POSSIBLE REQUIREMENTS ENGINEERING TECHNIQUES}

We have performed in depth literature study for identification of available RE techniques [24][23][22]. We have gathered valuable information related to RE techniques and their related parameters from research papers published in IEEE conferences, reputed IEEE transactions, Scopus indexed journals, Elsevier, white papers, existing project documents and experience reports [16][20][8][24][23]. We have found that requirements engineering is not only affected by problem domain perspective but also with the project characteristics, developer experience and knowledge, stakeholder's knowledge, organization and social related parameters. We have identified $55 \mathrm{RE}$ techniques. All the RE techniques and their related applicability in RE process is illustrated in Table 1[13][21][15] [14][20][23][22]. Several techniques are available for various phases of Requirements Engineering. Following criteria is accepted for the cataloging all RE techniques: -

- RE techniques that were widely used commonly were listed.

- RE techniques that usually use for at least two phases of $\mathrm{RE}$ process model were given priority as use of single technique in various phases may require less expertise of RE engineers and project team will also feel comfortable due to familiarity with techniques.

- RE techniques that already used in previous research journals whose results and feedback available were chosen so that output of this framework can be easily compare with previous research work.

- RE techniques were selected in such a way that almost every attribute can be addressed.

- RE techniques were selected in such a way that physical estimation of maximum attributes was possible.

Cataloging and listing of existing techniques needs description of each attributes that demonstrate these techniques. Table 1 depicts of cataloging of techniques identified in this research and their contribution in a particular phase of RE.

Table 1: RE Techniques

\begin{tabular}{|l|l|l|}
\hline Serial Number & Technique Name & $\begin{array}{l}\text { Major contribution of specific step } \\
\text { of RE }\end{array}$ \\
\hline 1. & Brain Storming and Idea Reduction & Requirements Elicitation \\
\hline 2. & Observation & Requirements Elicitation \\
\hline 3. & Ethnography & Requirements Elicitation \\
\hline 4. & Focus Group & Requirements Elicitation \\
\hline 5. & Interview & Requirements Elicitation \\
\hline 6. & Contextual Inquiry & Requirements Elicitation \\
\hline 7. & Analysis Laddering & Requirements Elicitation \\
\hline 8. & Viewpoint-Based Elicitation & Requirements Analysis \\
\hline 9. & Exploratory Prototypes & $\begin{array}{l}\text { Requirements Elicitation, Analysis, } \\
\text { Verification and Validation }\end{array}$ \\
\hline 10. & Evolutionary Prototypes & $\begin{array}{l}\text { Requirements Elicitation, Analysis, } \\
\text { Verification and Validation }\end{array}$ \\
\hline 11. & Viewpoint-Based Analysis & Requirements Analysis \\
\hline 12. & Repertory Grids & Requirements Elicitation \\
\hline 13. & User Scenarios & Requirements Elicitation \\
\hline 14. & JAD & Requirements Elicitation \\
\hline 15. & Soft System Methodology (SSM) & Requirements Analysis \\
\hline 16. & Goal-Oriented Analysis & Requirements Analysis \\
\hline
\end{tabular}




\begin{tabular}{|c|c|c|}
\hline 17. & Viewpoint-Based Documentation & Requirements Documentation \\
\hline 18. & Workshop & Requirements Elicitation \\
\hline 19. & Representation Modeling & Requirements Analysis \\
\hline 20. & Functional Decomposition & Requirements Analysis \\
\hline 21. & Decision Tables & $\begin{array}{l}\text { Requirements Analysis, } \\
\text { Documentation and Verification }\end{array}$ \\
\hline 22. & State Machine & $\begin{array}{l}\text { Requirements Analysis, } \\
\text { Documentation and Verification }\end{array}$ \\
\hline 23. & State Charts & $\begin{array}{l}\text { Requirements Analysis, } \\
\text { Documentation and Verification }\end{array}$ \\
\hline 24. & Petri-nets & $\begin{array}{l}\text { Requirements Analysis, } \\
\text { Documentation and Verification }\end{array}$ \\
\hline 25. & Structured Analysis & $\begin{array}{l}\text { Requirements Analysis, } \\
\text { Documentation and Verification }\end{array}$ \\
\hline 26. & Real Time Structured Analysis & $\begin{array}{l}\text { Requirements Analysis, } \\
\text { Documentation and Verification }\end{array}$ \\
\hline 27. & Object Oriented Analysis & $\begin{array}{l}\text { Requirements Analysis, } \\
\text { Documentation and Verification }\end{array}$ \\
\hline 28. & Problem Frame Oriented Analysis & $\begin{array}{l}\text { Requirements Analysis, } \\
\text { Documentation and Verification }\end{array}$ \\
\hline 29. & Survey/Questionnaire & Requirements Elicitation \\
\hline 30. & Introspection & Requirements Elicitation \\
\hline 31. & Document Analysis & Requirements Elicitation \\
\hline 32. & Prototyping & Requirements Elicitation \\
\hline 33. & Card Sorting & Requirements Elicitation \\
\hline 34. & & Requirements Documentation \\
\hline 35. & Fault Tree Analysis & Requirements Analysis \\
\hline 36. & Specification & Requirements Documentation \\
\hline 37. & $\begin{array}{l}\text { Viewpoint- Based Verification and } \\
\text { Validation }\end{array}$ & Requirements Documentation \\
\hline 38. & Unified Modeling Language (UML) & Requirements Documentation \\
\hline 39. & Zed (Z) & $\begin{array}{l}\text { Requirements Documentation, } \\
\text { Analysis, Verification }\end{array}$ \\
\hline 40. & LOTOS & $\begin{array}{ll}\text { Requirements } & \text { Documentation, } \\
\text { Analysis, Validation } & \end{array}$ \\
\hline 41. & SDL & \begin{tabular}{|ll} 
Requirements & Documentation, \\
Analysis, Validation & \\
\end{tabular} \\
\hline 42. & Formal Requirements Inspection & $\begin{array}{lll}\begin{array}{l}\text { Requirements } \\
\text { Validation }\end{array} & \text { Verification } & \text { and } \\
\end{array}$ \\
\hline 43. & Requirements Checklist & \begin{tabular}{|lll} 
Requirements & Verification \\
Validation & & and \\
\end{tabular} \\
\hline 44. & Utility Test & \begin{tabular}{|lll} 
Requirements & Verification & and \\
Validation & & \\
\end{tabular} \\
\hline 45. & Brain Storming & Requirements Elicitation \\
\hline 46. & Bubble Sort Technique & Requirements Elicitation \\
\hline 47. & MOSCOW & Requirements Prioritization \\
\hline 48. & Hundred Dollar Method & Requirements Prioritization \\
\hline 49. & Analytical Hierarchical Processing & Requirements Prioritization \\
\hline 50. & Numerical Assignment & Requirements Prioritization \\
\hline
\end{tabular}


An Automated Tool for Analysis of Requirements Engineering Techniques

\begin{tabular}{|l|l|l|}
\hline 51. & Value Oriented Prioritization & Requirements Prioritization \\
\hline 52. & Priority Weighting & Requirements Prioritization \\
\hline 53. & Cumulative Voting & Requirements Prioritization \\
\hline 54. & Playing Game & Requirements Prioritization \\
\hline 55. & Vienna Development Method (VDM) & $\begin{array}{l}\text { Requirements Documentation, } \\
\text { Analysis, Validation }\end{array}$ \\
\hline
\end{tabular}

\section{IDENTIFICATION AND ANALYSIS OF ATTRIBUTES OF REQUIREMENT ENGINEERING TECHNIQUES AND FORMATION OF INPUT MATRIX}

Attributes are the parameters that differentiate each and every technique from one another. Attributes selection focuses on five major factors [24]: Project domain attributes, software process model attributes, organizational aspects, analyst understandability, client's preferences and experience. Both functional and nonfunctional requirements were considered for RE technique attributes selection. Attributes analysis process follows following steps:

- RE technique attributes were listed from existing research papers and journals as their results can be compared with our research.

Table 2 Attributes of Requirements Engineering Techniques

\begin{tabular}{|c|c|}
\hline Serial No. & Attributes \\
\hline 1. & Scalability \\
\hline 2. & Feasibility \\
\hline 3. & Degree of Communication \\
\hline 4. & Use of latest calculation and scientific tools \\
\hline 5. & Modularity \\
\hline 6. & Express ability \\
\hline 7. & Reusability \\
\hline 8. & Requirements verification capability \\
\hline 9. & Requirements pre processing capability \\
\hline 10. & Validation capability \\
\hline 11. & Number of RE phases covers \\
\hline 12. & Social issues understanding capabilities \\
\hline 13. & Capability of gathering and use of Non-functional requirements \\
\hline 14. & Ability to get domain knowledge \\
\hline 15. & Customer Negotiation capabilities \\
\hline 16. & Capability to get implicit knowledge \\
\hline 17 & Ability to identify stakeholders \\
\hline 18 & Capability to identify non-functional requirements \\
\hline 19 & Competence to identify various viewpoints \\
\hline 20 & Ability to model and understand requirements \\
\hline 21 & Understanding ability for the notations used in analysis \\
\hline 22 & Competence to facilitate the negotiation with customer \\
\hline 23 & Competence to prioritize the requirements \\
\hline 24 & Capability to identify the accessibility of the system \\
\hline 25 & Capacity to model interface requirements \\
\hline 26 & Capability to identify and support requirements reuse \\
\hline 27 & Capabilities to identify the unambiguous requirements \\
\hline 28 & Completeness of semantics of the notation \\
\hline 29 & Capacity to write unambiguous and precise requirements by using the notation \\
\hline
\end{tabular}
cover all major factors of RE process.

- RE technique attribute were analyzed in such a way that they can be analyzed or we can say estimated from set of rules. For example, complexity is rated Very High if higher mathematical calculation involves, time consuming process, east derivation may tend wrong results etc. Cost may trea low if technique may implement with existing resources,

- RE technique attribute analysis and weight is assign to Withibute.

With the in-depth analysis, we recognize 38 attributes for RE techniques. Below Table 2 shows list of attributes that link with the one of the phases of the RE process.

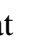




\begin{tabular}{|l|l|}
\hline 30 & Capabilities to write complete requirements \\
\hline 31 & Competence for requirements management Modularity \\
\hline 32 & Capabilities to identify the interaction \\
\hline 33 & Capabilities to recognize the incomplete requirements \\
\hline 34 & Capabilities to provision COTS-based RE process \\
\hline 35 & Maturity of the supportive tool \\
\hline 36 & Learning curve (also named as Introductory cost) \\
\hline 37 & Cost Application Development \\
\hline 38 & Techniques Complexity \\
\hline
\end{tabular}

To each attribute, there is a list of measures and conditions to certify its measurability. Weight Assignment Method is used for all attributes, i.e. the attribute values are set as not relevant, very low (very small), low(small), medium, high(large) and very high (very large). The weight assignment method is shown in Table 3. An ordinal scale is used in weight assignment method for all attributes. For example, if project Size (no. of requirements) are less than 10 it is considered as Very Small or Very Low. If the project Size is greater than 5000 so it is considered as Very Large project or Very High, so associated value is assigned. This way an input matrix is formed.

Table 3 Weight Assignment Method

\begin{tabular}{|l|l|}
\hline $\begin{array}{l}\text { Very High/ } \\
\text { Very Large }\end{array}$ & 1 \\
\hline High/Large & 0.8 \\
\hline Medium & 0.6 \\
\hline Low/Small & 0.4 \\
\hline $\begin{array}{l}\text { Very Low/ Very } \\
\text { Small }\end{array}$ & 0.2 \\
\hline Not Related & 0 \\
\hline
\end{tabular}

\section{DETAILED ANALYSIS OF THE TECHNIQUES USING A CLUSTERING METHOD}

Clustering is a technique of unsupervised learning and has been extensively used for statistical data analysis. It is used in several domains viz. in medical domain for medical data analysis, data mining, and market data analysis. Clustering systematizes the data through extracting the fundamental assembly either as a set of entities or as an order of sets [5]. This means that clustering methodology let data elements having alike attributes to be systematized into groups. There are a various clustering method exists, such as K-Means clustering, Hierarchy Clustering and Fuzzy Clustering [6][10][11][17]. The Fuzzy C- mean clustering method is used in this research. Fuzzy Clustering is used for generating such set which depicts membership weight of each cluster member. The benefits of using Fuzzy $\mathrm{C}$ mean clustering are [5] [12][19]:

- It suggests bunch of RE techniques rather than single one.

- It suggests equally competent RE technique as an alternate.

- It accommodates change in environment variables and suggest alternate bunch in changed condition.

- Equally opposite techniques are also suggested.

- It permits regular associations of data points to clusters restrained as degrees in $[0,1]$. This offer the flexibility to specify that any data points can have its place in more than one cluster.

The elementary principle of Fuzzy Clustering algorithm is to minimize the below objective function [12]:

$$
\begin{gathered}
J_{m}=\sum_{i=1}^{N} \sum_{j=1}^{C} u_{i j}^{m}\left\|x_{i}-c_{j}\right\|^{2} \\
1 \leq m<\infty
\end{gathered}
$$

In the above mentioned objective function, $\mathrm{m}$ is any real number which is greater than $1, \mathbf{u}_{\mathbf{i j}}$ depicts the membership of $\mathrm{x}_{\mathrm{i}}$ in cluster $\mathrm{j}, \mathrm{x}_{\mathbf{i}}$ is the $\mathrm{i}^{\text {th }}$ of $\mathrm{d}$-dimensional measured data, $\mathrm{c}_{\mathrm{j}}$ is the d-dimensional center of the cluster, and $\|*\|$ is any norm depicting the resemblance between any measured data and the center. Fuzzy partitioning is accomplished by an repetitive optimization of objective function along with the update of membership $\mathbf{u}_{\mathbf{i j}}$ and the cluster centers $\mathbf{c}_{\mathbf{j}}$ by:

$$
\begin{gathered}
u_{u=1}=\frac{1}{\sum_{i=1}^{c}\left(\frac{\left\|x_{j}-c_{j}\right\|}{\left\|x_{j}-c_{\lambda}\right\|}\right)^{\frac{2}{m-1}}} \\
c_{j}=\frac{\sum_{i=1}^{N} u_{j}^{m}-x_{j}}{\sum_{j=1}^{N} u_{j}^{m}}
\end{gathered}
$$

This repetition will come to an end when

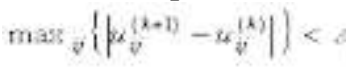

where end condition lies between 0 and 1 , while $\mathrm{k}$ represents iteration steps. This process congregates to local minimum or a saddle point of $\mathrm{J}_{\mathrm{m}}$. The proper algorithm is as follows:

1. Initialize $\mathrm{U}=\left[\mathrm{u}_{\mathrm{ij}}\right]$ matrix, $\mathrm{U}^{(0)}$

2. At k-step: calculate the centers vectors $\mathrm{C}^{(\mathrm{k})}=\left[c_{j}\right]$ with $\mathrm{U}^{(\mathrm{k})}$

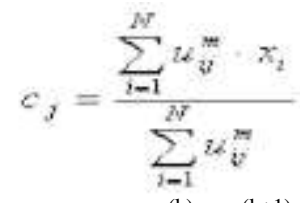

$$
\begin{aligned}
& \text { 3. Update } \mathrm{U}^{(\mathrm{k})}, \mathrm{U}^{(\mathrm{k}+1)}
\end{aligned}
$$

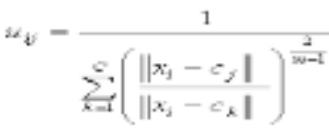

4. If $\left\|\mathrm{U}^{(\mathrm{k}+1)}-\mathrm{U}^{(\mathrm{k})}\right\|<\varepsilon$ then STOP; otherwise return to step 2 .

Published By: Blue Eyes Intelligence Engineering 
In FCM, data elements are approximately destined to distinct cluster by means of Membership Function, which signifies fuzzy behavior of this algorithm. To achieve that an appropriate matrix termed as $\mathrm{U}$ is build whose factors are numbered between 0 and 1 , and depicts the membership degree between data and centers of clusters. With the help of clustering we can take total advantage of the cohesiveness of the every RE technique in each cluster and also lessens the cost function. Clustering helps to assemble RE techniques with respect to their attributes. Techniques that makes their room in single cluster share common characteristics and create a foundation for selection to a particular problem domain.

\section{CASE STUDY}

To explore the advantages of proposed methodology a case study is conducted. However, in software engineering field case studies are the most effective way for the evaluation software engineering tools and techniques. When a client request for project development in a company, some know problem domain attributes is identified from client by requirements analyst. Table 3 depicts some known problem domain characteristics for this case study. This initial set of problem domain characteristics was used to choose best combination of RE techniques. These problem domain characteristics act as an input for performing clustering to get set of techniques for each relevant phase of RE. Figure 1 depicts the clustering of relevant RE techniques for this problem domain. The clusters of techniques are created via applying problem domain in our automated tool. Its very important to get all comprehensive set of techniques for each stages of requirements engineering. Table 4 briefly describe set of techniques for each phase of requirements engineering with their associated cluster values. Recommended Technique Set consists of all the techniques which comes as an output when we fed problem domain values to our automated tool.
Table 3 Problem domain with known characteristics

\begin{tabular}{|l|l|}
\hline Project Size & Large (1000-4000) \\
\hline Project Complexity & Very High \\
\hline Requirements Volatility & Very Low \\
\hline Degree of Criticalness & High \\
\hline Time and cost constraint & Low \\
\hline Project of existing domain & Existing \\
\hline
\end{tabular}

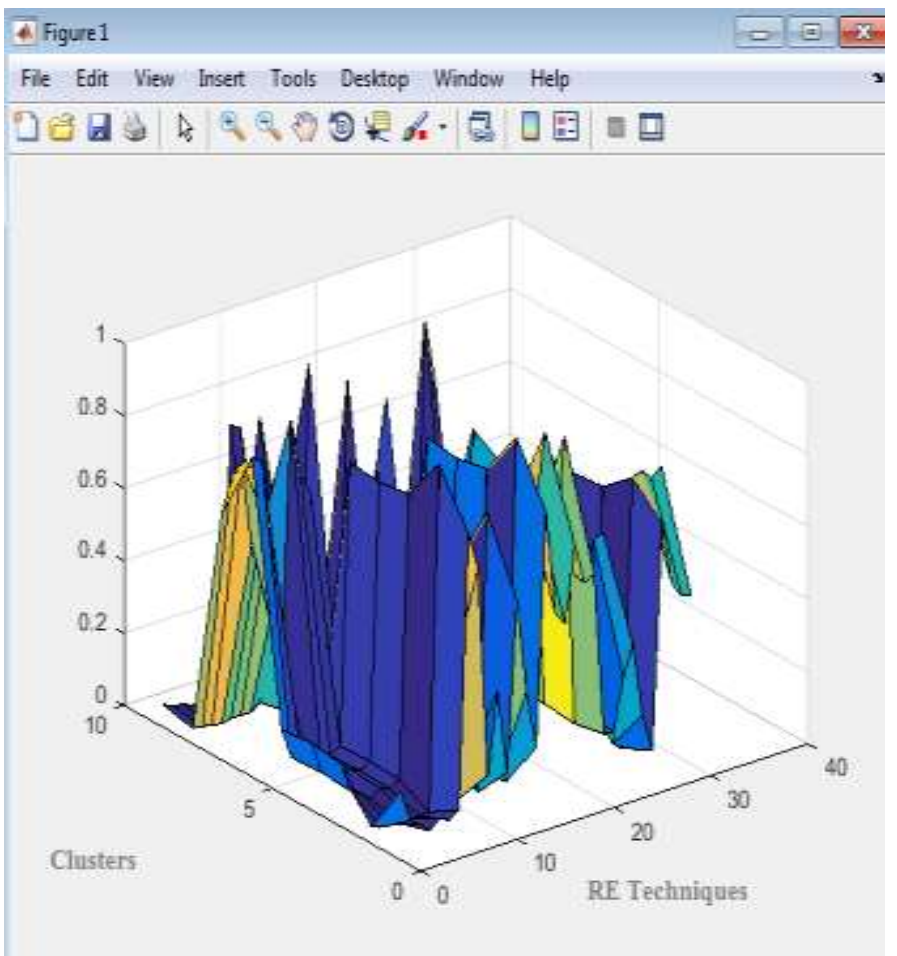

Figure 1 Clusters of RE technique 
Table 4 Recommended Techniques Sets

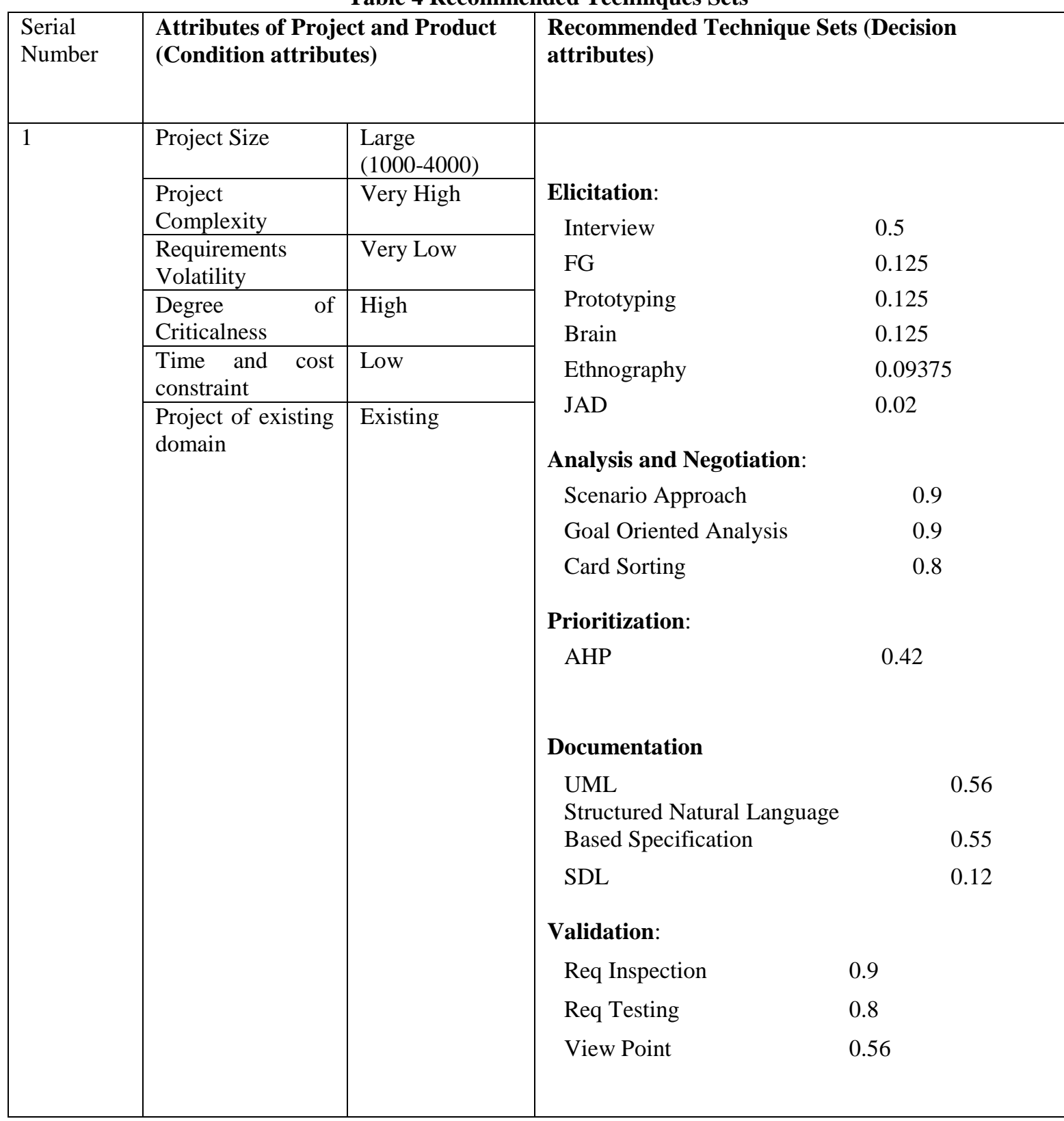

\section{CONCLUSION}

Selecting nearly correct RE techniques for software product development results in inclusive accomplishment of a software project. However, selection process completely depends on in-depth understanding of RE techniques and the associations between them. This research work helps to understand various RE technique and attribute assignment to each technique. The presented work depicts that clustering method is one of the most efficient method for analyzing RE techniques. Future work may be done to incorporate more RE techniques and analyzing the output with applying clustering method with added RE techniques. Our work is to create a decision support system. The integration of the clustering mechanism into the whole RE process model still needs to be done.

\section{REFERENCES}

1. Boehm BW, "Software Engineering Economics", Prentice Hall, 1981. https://dl.acm.org/citation.cfm?id=539425
2. Macaulay LA, "Requirements for Requirements Engineering Techniques”. IEEE Proceedings of ICRE, pp. $157 \quad-\quad 164, \quad 1996$ http://www.panda.sys.t.u-tokyo.ac.jp/kushiro/ReferenceP aper/Requirements\%20engineering/00491440.pdf

3. Sommerville I, Sawyer P, "Requirements Engineering: A Good Practice Guide", John Wiley and Sons, 1997. https://dl.acm.org/citation.cfm?id=549198

4. Kotonya G, Sommerville I, "RE Processes and Techniques”, John Wiley \& Sons Ltd, 1998.

5. Jain AK, Dubes RC, "Algorithms for Clustering Data". Prentice-Hall, 1998.

6. Glenn Fung June, "A Comprehensive Overview of Basic Clustering Algorithms" June 22, 2001. https://sites.cs.ucsb.edu/ veronika/MAE/clustering_over view 2001.pdf

7. Jiang L, Eberlein A, "Requirements Engineering: A Review and A Proposal", Proceedings of the Third ASERC Workshop on Quantitative and Software Engineering, Feb. 17- 18, Banff, Alberta, Canada, 2003. 
8. Hickey, A.M., Davis, A.M, "Elicitation technique Selection: how do experts do it?" Proceedings of the 11th IEEE International Requirements Engineering Conference, P169 - 178, 2003.

9. Hickey AM, Davis AM (2003), "Requirements elicitation and elicitation technique selection: A model for two knowledge intensive software development processes", Proceedings of the 36th Annual Hawaii International Conference on System Sciences, 6-9 Jan., Page(s): 96 $-1052003$.

10. Leo Wanner, "Introduction to Clustering Techniques", 2004.

https://people.ece.cornell.edu/land/courses/eceprojectslan d/STUDENTPROJ/2007to2008/ak364/491_ak364/cluste ring.pdf

11. Rui Xu and Donald Wunsch, "Survey of Clustering Algorithms", IEEE Transactions on Neural Networks, Volume 16, Issue 3, pp 645-678, May 2005. http://axon.cs.byu.edu/Dan/678/papers/Cluster/Xu.pdf

12. K Balaji and N Zacharias Juby, "Fuzzy c-means", 2007 https://static.aminer.org/pdf/PDF/000/271/379/unsupervi sed_clustering_methods_for_medical_data_an_applicatio n_to_thyroid.pdf

13. Dr. Archana Bhatnagar: Software Engineering, Publication: Ajmera Book Company, Tripolia Bazaar, Jaipur. Authored book for BCA Part-III of University of Rajasthan, September, 2010.

14. [14] Tiwari Saurabh, Rathore Singh Santosh, and Gupta Atul, "Selecting Requirement Elicitation Techniques for Software Projects", CSI 6th International Conference on Software Engineering, CONSEG 2012. researchgate.net/publication/255720277_Selecting_requi rement_elicitation_techniques_for_software_projects

15. Dhirendra Pandey, "The Research Roadmap of Requirement Validation", International Journal of Advanced Research in Computer Science, Volume 4, No. 4, March-April 2013, https://www.researchgate.net/publication/291834131 Th e_Research_Roadmap_of_Requirement_Validation

16. Batra, Mona and Pandey S.K., "Security Testing in Requirements Phase of SDLC", International Journal of Computer Applications (0975 - 8887) Volume 68- No.9, April 2013. https://pdfs.semanticscholar.org/a8a5/b7f7c6da7f61c693 c59ca2ba5ccb31b0595d.pdf

17. Mann Amandeep Kaur \& Kaur Navneet, "Review Paper on Clustering Techniques ”, Global Journal of Computer Science and Technology Software \& Data Engineering, Volume 13 Issue 5 Version 1.02013. https://pdfs.semanticscholar.org/12f4/a1852e95939080b6 95edbb7d23183918689e.pdf

18. Standish chaos report, 2014 https://www.projectsmart.co.uk/white-papers/chaos-repor t.pdf

19. Kiweewa Abdu Kalema, Bukenya Faiza, Alinda Alias Rose, "A review and analysis of fuzzy-c means clustering techniques", International Journal of Scientific \& Engineering Research, Volume 5, Issue 11, November-2014, ISSN 2229-5518. https://pdfs.semanticscholar.org/e279/af583103411125c9 5fa90137018c3783af3c.pdf

20. Batra Mona and Bhatnagar Dr. Archana, "Descriptive Literature Review of Requirements Engineering Models", International Journal of Advanced Research in Computer Science and Software Engineering, Volume 5, Issue 2, February 2015. http://ijarcsse.com/Before_August_2017/docs/papers/Vol ume_5/2_February2015/V5I2-0331.pdf

21. Khan Hameed Ullah, Asghar Ikram, A.K. Ghayyur Shahbaz and Raza Asian Mohsin, "An Empirical Study of Software Requirements Verification and Validation
Techniques along their Mitigation Strategies", Journal of Computer and Information Systems (ISSN: $2321-5658$ ) Volume 03- Issue 03, August 2015 Asian Online Journalswww.ajouronline.com).

https://pdfs.semanticscholar.org/3d5f/0d3ede3f1568fc2be 809a345aed7e94f1234.pdf

22. Batra, Mona and Bhatnagar Dr. Archana, "Requirements Prioritization: A Review", International Journal of Advanced Research in Science, Engineering and Technology, Vol. 3, Issue 11, November 2016. http://www.ijarset.com/upload/2016/november/6_IJARS ET_monabatra.pdf

23. Batra Mona and Bhatnagar Dr. Archana, "An Experimental Survey to Find Application Specific Elicitation Technique", 4th International Conference on "Computing for Sustainable Global Development", 01st 03rd March, 2017 Proceedings of the 11th INDIACom,2017 New Delhi (INDIA) https://www.bvicam.ac.in/news/INDIACom\%202017\%2 OProceedings/Main/papers/768.pdf

24. Batra Mona, Bhatnagar Dr. Archana, "A Requirements Elicitation Approach: Five Factor Approach", International Journal of Engineering and Advanced Technology (IJEAT) ISSN: 2249 - 8958, Volume-8 $\begin{array}{llll}\text { Issue-5C, } & \text { May } & 2019 & \text { India }\end{array}$ https://www.ijeat.org/wp-content/uploads/papers/v8i5C/ E11900585C19.pdf 